\title{
Establishment of 5-fluorouracil-resistant oral squamous cell carcinoma cell lines with epithelial to mesenchymal transition changes
}

\author{
KOJI HARADA, TARANNUM FERDOUS and YOSHIYA UEYAMA \\ Department of Oral and Maxillofacial Surgery, Yamaguchi University Graduate School of Medicine, Ube, Japan
}

Received November 7, 2013; Accepted January 8, 2014

DOI: $10.3892 /$ ijo.2014.2270

\begin{abstract}
Fluorouracil (5-FU) has been used for oral squamous cell carcinoma (OSCC) treatments, and the acquisition of resistance is the major problem to successful OSCC treatment. It has been reported that the epithelial to mesenchymal transition (EMT) is associated with chemoresistance in several types of cancers. In the present study, we established 5-FU-resistant OSCC cell lines (HSC2/FU and HSC4/FU), and aimed to elucidate the mechanism(s) involved in resistance in association with its EMT characteristics. MTT assay revealed that $\mathrm{HSC} 2 / \mathrm{FU}$ is about 14 -fold more resistant compared to $\mathrm{HSC} 2$, and $\mathrm{HSC} 4 / \mathrm{FU}$ is 5-fold more resistant compared to HSC4. TUNEL assay also showed a dramatically decreased number of apoptotic cells in the 5-FU-resistant OSCC cell lines compared to each parental cell after treatment with 5-FU. Moreover, the 5-FU-resistant OSCC cell lines had typical morphologic phenotypes of EMT; loss of cell-cell adhesion, increased formation of pseudopodia and spindle-shaped morphology. Western blot analysis showed downregulated E-cadherin, and upregulated N-cadherin and Twist in the 5-FU-resistant OSCC cell lines. Results of our tumor xenograft studies coincide with our in vitro study data that confirmed the 5-FU resistant nature of HSC2/FU and HSC4/FU tumors. Moreover, immunohistochemistry showed that EMT changes (downregulated E-cadherin, and upregulated Twist and N-cadherin) occurred in the 5-FU-resistant xenografted tumor cells. These results suggest that EMT has important roles in the 5-FU-resistant OSCC cells, and that these resistant cells may be considered as useful tools for understanding the mechanisms involved in 5-FU resistance in OSCC.
\end{abstract}

Correspondence to: Dr Koji Harada, Department of Oral and Maxillofacial Surgery, Yamaguchi University Graduate School of Medicine, 1-1-1, Minamikogushi, Ube 755-8505, Japan

E-mail: harako@yamaguchi-u.ac.jp

Key words: oral squamous cell carcinoma, 5-fluorouracil, resistance, epithelial-to-mesenchymal transition

\section{Introduction}

The incidence of oral squamous cell carcinoma (OSCC) is increasing gradually, and about 300,000 patients are annually estimated to develop oral cancer worldwide (1-3). OSCC is the most common malignant neoplasm of the oral cavity and represents about $90 \%$ of all oral malignancies (4). Though the standard treatment for OSCC is thought to be surgical operation, we often select chemotherapy for patients with advanced or recurrent OSCC. Among anticancer drugs, 5-florouracil (5-FU) is a basic drug for cancers of the digestive organs including OSCC, and it has wide clinical application. After discovery of 5-FU by Heidelberger in 1957, 5-FU has been in use for over 50 years (5). However, resistance to 5 -FU is a major problem for successful cancer treatment, and the mechanism of 5-FU-resistance in cancers is still not clear.

Epithelial-to-mesenchymal transition (EMT) causes profound morphological and phenotypic changes to a cell (6). EMT is a process that enables epithelial cells to lose their epithelial characteristics and acquire mesenchymal cell characteristics. Briefly, epithelial cell becomes spindle-shaped, lose their characteristic polarization, interacting with each other only through focal points as mesenchymal cells (7) and development of pseudopodia is observed. Moreover, epithelial cell phenotype markers such as E-cadherin is downregulated, and mesenchymal markers including vimentin, Snail, N-cadherin and Twist are upregulated during EMT (8). It has been reported that EMT is important in tumor progression, metastasis and chemoresistance $(9,10)$. In addition, it has been demonstrated that the acquisition of EMT is related to cancer stem cells (CSC) which contributes to the chemoresistance as well as tumor progression and metastasis $(11,12)$.

In the present study, we established two 5-FU-resistant OSCC cell lines (HSC2/FU and HSC4/FU) and investigated the mechanisms of 5-FU resistance in association with EMT characteristics.

\section{Materials and methods}

Cell culture and establishment of 5-FU-resistant cell lines. HSC2 and HSC4 cells were purchased from Cell Bank, RIKEN BioResource Center (Ibaraki, Japan). Both cell lines were exposed to step-wise increasing concentrations of 5-FU 
(Wako, Osaka, Japan). The cells that survived in culture medium including 5-FU for a year, were cloned by limiting dilution. Cells were cultured in Dulbecco's modified Eagle's medium (DMEM) (Sigma-Aldrich, St. Louis, MO, USA) supplemented with $10 \%$ fetal bovine serum (FBS) (Invitrogen, Carlsbad, CA, USA), $100 \mu \mathrm{g} / \mathrm{ml}$ streptomycin, $100 \mathrm{U} / \mathrm{ml}$ penicillin (Invitrogen) in a humidified atmosphere containing $5 \% \mathrm{CO}_{2}$.

In vitro cell growth assay. Cells $\left(5 \times 10^{3}\right.$ cells per well) were seeded on 96-well plates (Becton-Dickinson Labware, Franklin lakes, NJ, USA) in DMEM supplemented with $10 \%$ FBS. Twenty-four hours later, the cells were treated with 5-FU (0, 2 , 4 and $8 \mu \mathrm{g} / \mathrm{ml})$. After $48 \mathrm{~h}, 3$-(4,5-dimethylthiazol-2-yl)-2,5diphenyltetrazolium bromide (MTT) was added to each well ( $25 \mu \mathrm{l} /$ well) and incubated for $4 \mathrm{~h}$. The blue dye taken up by cells was dissolved in dimethyl sulfoxide (100 $\mu \mathrm{l} /$ well), and the absorbance was measured with a spectrophotometer (Bio-Rad Laboratories, Hercules, CA, USA) at $490 \mathrm{~nm}$. All assays were run in triplicate.

Terminal deoxyribonucleotidyl transferase-mediated dUTP nick end labeling (TUNEL) assay. Cells $\left(5 \times 10^{3}\right.$ cells per well) were seeded on micro-cover glass (Matsunami Glass Ind., Osaka, Japan) in DMEM containing 10\% FBS. After incubation for $24 \mathrm{~h}$, the culture medium was replaced with DMEM with $10 \% \mathrm{FBS}$ and $2 \mu \mathrm{g} / \mathrm{ml}$ of 5-FU. After further incubation for $48 \mathrm{~h}$, the cells on the micro-cover glass were washed twice with phosphate-buffered saline (PBS), air dried, and fixed in $4 \%$ paraformaldehyde at room temperature for $30 \mathrm{~min}$. TUNEL assay was performed using a DeadEnd ${ }^{\mathrm{TM}}$ Colorimetric TUNEL System according to the manufacturer's instructions (Promega Corporation, Madison, WI, USA). Briefly, the cells on the micro-cover glass were incubated in $20 \mu \mathrm{g} / \mathrm{ml}$ proteinase $\mathrm{K}$ for $15 \mathrm{~min}$. Endogenous peroxidase of cells on the micro-cover glass was blocked by incubating in a $3 \%$ hydrogen peroxide solution for $5 \mathrm{~min}$ after cells were rinsed in distilled water. After being washed with PBS (0.05 M phosphate buffer containing $0.145 \mathrm{M}$ sodium chloride, $\mathrm{pH} 7.4$ ), the cells were incubated with equilibration buffer and then TdT enzyme in a humidified chamber at $37^{\circ} \mathrm{C}$ for $60 \mathrm{~min}$. They were subsequently put into pre-warmed working strength stop wash buffer for $10 \mathrm{~min}$. After being rinsed in PBS, the cells were incubated with antidigoxigenin-peroxidase conjugate for $30 \mathrm{~min}$. Peroxidase activity in each cell was demonstrated by the application of diaminobenzidine. Hematoxylin was used as a counterstain. At least 1,000 cells were counted under a microscope in several random fields of each microcover glass. The number of apoptotic cell was calculated the number of TUNEL positive cells divided by the total number of counted cells and the result was expressed as a percentage.

In the same manner as above, TUNEL assay was performed in 4- $\mu$ m-thick paraffin sections of tumor using a DeadEnd Colorimetric TUNEL System according to the manufacturer's instructions (Promega).

Western blot analysis. Cells were lysed with RIPA Buffer (Thermo scientific, Rockford, IL, USA). Whole cell lysates were subjected to electrophoresis on $10 \%$ SDS-polyacrylamide gels, and then transferred to a
PVDF membrane. The membranes were incubated with anti-E-cadherin rabbit polyclonal antibody (Santa Cruz Biotechnology, Santa Cruz, CA, USA), anti-N-cadherin rabbit monoclonal antibody (Epitomics, Burlingame, CA, USA), anti-Twist mouse monoclonal antibody (Epitomics). The antibody was detected using a chromogenic immunodetection system, WesternBreeze (Invitrogen) according to the manufacturer's instructions. Also, anti- $\alpha$-tubulin monoclonal antibody (Santa Cruz Biotechnology) was used for normalization of western blot analysis.

Nude mice. Female athymic nude mice with CAnN. Cg-Foxnlnu/CrlCrlj genetic background (CLEA Japan, Inc., Tokyo, Japan) were purchased at 4 weeks of age and kept under sterile conditions in a pathogen-free environment. The mice were provided with sterile water and food ad libitum and all manipulations were carried out aseptically inside a laminar flow hood. The mice were maintained and were handled in accordance with the Guidelines for Animal Experimentation of Yamaguchi University.

In vivo tumor growth assay. The effect of 5-FU treatment was assessed by inoculation of cells into 5-week-old female athymic nude mice. Cells $\left(1 \times 10^{6}\right)$ were suspended in $0.1 \mathrm{ml}$ of serum-free medium and injected into the subcutaneous tissue of mice (average weight $15.0 \mathrm{~g}$ ) using a 27-gauge needle. Tumors at the inoculation site were monitored and measured. When the tumors reached $100-150 \mathrm{~mm}^{3}$ in volume, they were divided into 4 groups, and treated with 5-FU for 3 weeks. Briefly, 5-FU (15 mg/kg) was injected into the peritoneal cavity for 3 weeks ( 7 times/week). Also, mice in control group were received saline $(100 \mu \mathrm{l})$ by peritumoral injection. The tumors were measured every two days and the tumor volumes were calculated. At 21 days, mice were sacrificed by cervical dislocation and the tumors were dissected out, fixed in neutral-buffered formalin and embedded in paraffin for further study.

Statistical analysis. All statistical significance was set at $\mathrm{P}<0$.05. Statistical analyses were performed using StatView software (version 5.0J, SAS Institute Inc., Cary, NC, USA).

\section{Results}

Cell growth. Both HSC2 and HSC4 cells were treated with increasing concentrations of 5-FU up to $10 \mu \mathrm{g} / \mathrm{ml}$ to obtain 5-FU-resistant cells. In vitro cell growth inhibition assay was performed occasionally to determine the resistance nature of the cells and HSC2/FU and HSC4/FU were established almost one year later. There were no significant differences in cellular proliferation between HSC2 and HSC2/FU, and between HSC4 and HSC4/FU (Fig. 1).

Effects of 5-FU on the growth of parental and 5-FU-resistant OSCC cells in vitro. To compare the growth inhibitory effect of 5-FU between parental and resistant cell lines, we treated the cells with various concentrations of 5-FU. The inhibitory concentration $\left(\mathrm{IC}_{50}\right)$ data indicated that the 5-FU-resistance levels of $\mathrm{HSC} 2 / \mathrm{FU}\left(\mathrm{IC}_{50}, 14.0 \mu \mathrm{g} / \mathrm{ml}\right)$ were 14 -fold greater than that of the HSC2 $\left(\mathrm{IC}_{50}, 1.0 \mu \mathrm{g} / \mathrm{ml}\right)$ (Fig. 2A), and the 


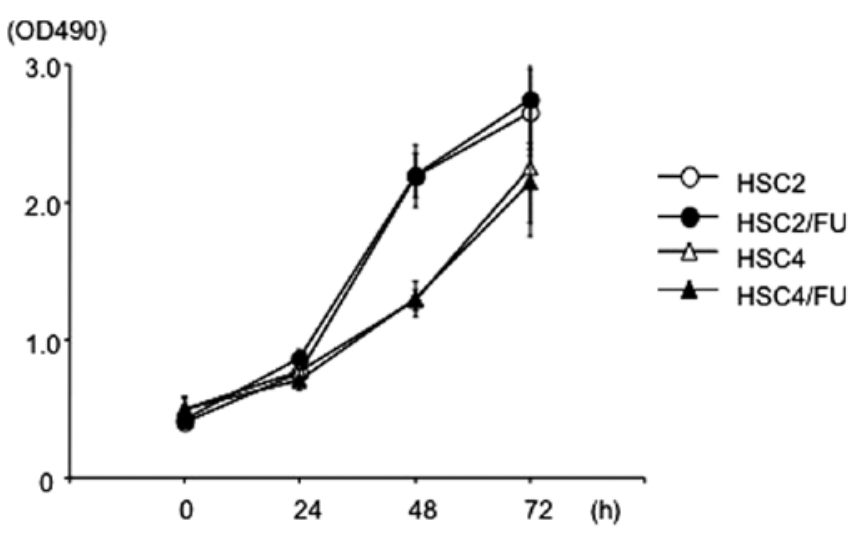

Figure 1. Cell growth assay. Cells $\left(5 \times 10^{3}\right.$ cells per well) were seeded on 96-well plates, and cultured for $72 \mathrm{~h}$. Cell growth was evaluated by MTT assay. There was no significant difference in cellular proliferation between HSC 2 and HSC2/FU, and between HSC4 and HSC4/FU. Error bars represent the standard deviation of the mean of three independent experiments.

5-FU-resistance levels of $\mathrm{HSC} 4 / \mathrm{FU}$ cells $\left(\mathrm{IC}_{50}, 7.0 \mu \mathrm{g} / \mathrm{ml}\right)$ were 5 -fold greater than that of the $\mathrm{HSC} 4\left(\mathrm{IC}_{50}, 1.4 \mu \mathrm{g} / \mathrm{ml}\right)$ (Fig. 2B).

Effects of 5-FU on apoptosis of parental and 5-FU-resistant OSCC cells. TUNEL staining showed a remarkable increase in the number of HSC2 cells exposed to 5-FU that were stained brown, which indicated the occurrence of apoptosis; whereas 5-FU-induced apoptosis was less evident in the HSC2/FU cells. Similarly, 5-FU-induced apoptosis occurred at an increased rate in HSC4 compared to HSC4/FU cells (Fig. 3A). In both cases, the number of apoptotic cells were significantly less in the 5-FU-resistant OSCC cells compared to the parental cell lines (Fig. 3B).

Cell morphology of 5-FU-resistant OSCC cell lines. The 5-FU-resistant cells, HSC2/FU and HSC4/FU, were morphologically distinct from their parental cell lines (Fig. 4). The resistant cells had lost the characteristics of cell-cell adhesion, developed spindle-shaped morphology and showed pseudopodia; which are typical phenotypes of EMT.

Expression of E-cadherin, $N$-cadherin and Twist in parental and 5-FU-resistant OSCC cells in vitro. Unlike epithelial cells that express high levels of E-cadherin, mesenchymal cells express $\mathrm{N}$-cadherin. Our western blot analysis showed decreased E-cadherin and increased $\mathrm{N}$-cadherin and Twist in the $\mathrm{HSC} 2 / \mathrm{FU}$ and $\mathrm{HSC} 4 / \mathrm{FU}$ cells in vitro compared to the parental cell lines (Fig. 5).

Effects of 5-FU on the growth and apoptosis of parental and 5-FU-resistant OSCC tumors in vivo. Tumor xenograft studies demonstrated that $\mathrm{HSC} 2 / \mathrm{FU}$ and $\mathrm{HSC} 4 / \mathrm{FU}$ tumors are resistant to 5-FU when compared to $\mathrm{HSC} 2$ and $\mathrm{HSC} 4$ tumors (Fig. 6). Briefly, tumor volume of HSC2 and HSC4 was significantly decreased by 5-FU administration though HSC2/FU and HSC4/FU tumors were not affected by $5-\mathrm{FU}$ injection. Moreover, TUNEL assay showed a significant decreased number of apoptotic cells in 5-FU-resistant tumors after treatment with 5-FU (Fig. 7).
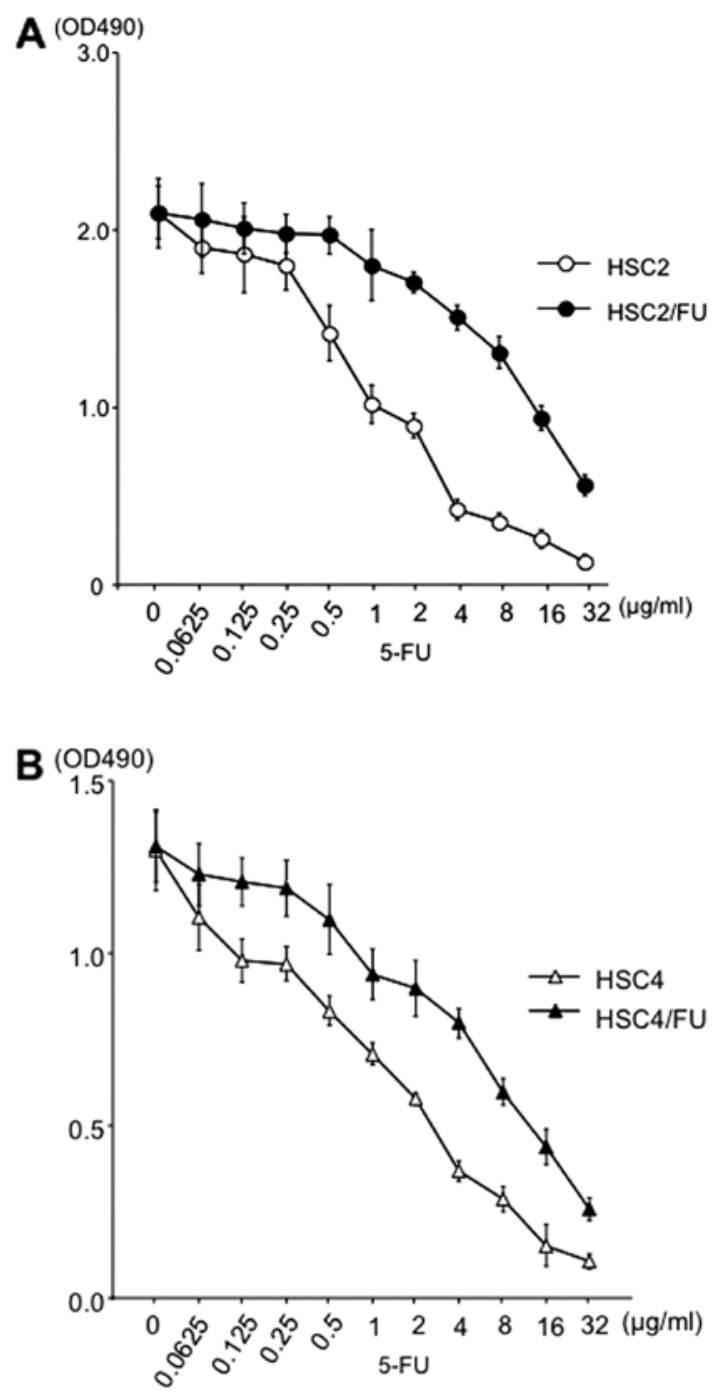

Figure 2. Chemosensitivity assay. (A) $\mathrm{IC}_{50}$ values of 5-FU for the HSC2/ FU and HSC2 are 14.0 and $1.0 \mu \mathrm{g} / \mathrm{ml}$, respectively. Therefore, the 5-FU resistance of the $\mathrm{HSC} 2 / \mathrm{FU}$ is 14 -fold greater than that of the $\mathrm{HSC} 2$. (B) $\mathrm{IC}_{50}$ values of 5-FU for the HSC4/FU and HSC4 are 7.0 and $1.4 \mu \mathrm{g} / \mathrm{ml}$, respectively. Therefore, the 5-FU resistance of the HSC4/FU is 5-fold greater than that of the HSC4. Error bars represent the standard deviation of the mean of three independent experiments.

Expression of E-cadherin, $N$-cadherin and Twist in parental and 5-FU-resistant OSCC tumors in vivo. We carried out immunohistochemistry experiments to evaluate the expression pattern of EMT-related factors (E-cadherin, N-cadherin and Twist) between 5-FU-sensitive tumors and 5-FU-resistant tumors. The expression of E-cadherin was markedly decreased in 5-FU-resistant tumors, and the expression of $\mathrm{N}$-cadherin and Twist was increased in 5-FU-resistant tumors (Fig. 8).

\section{Discussion}

5-FU has widespread clinical use for digestive organ cancer treatments (13-16) and it is also a key drug for OSCC treatments. 5 -FU has been preferentially used in combination with other chemotherapeutic drugs such as cisplatin and/or docetaxel for head and neck cancer treatment including OSCC (17-19). The 


\section{A}
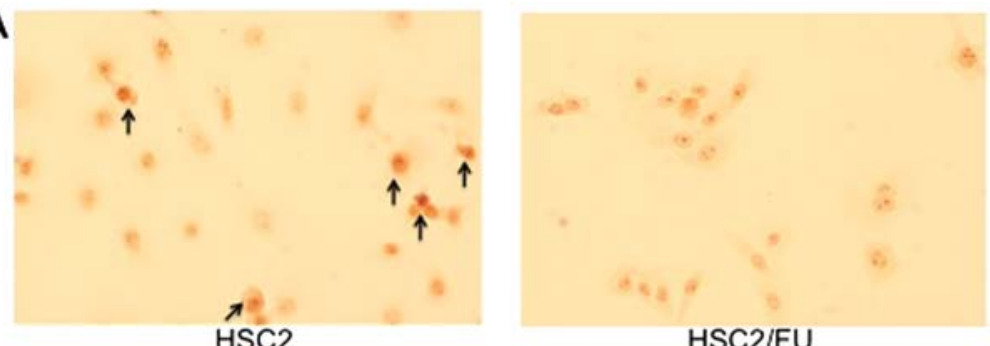

$\mathrm{HSC} 2 / \mathrm{FU}$

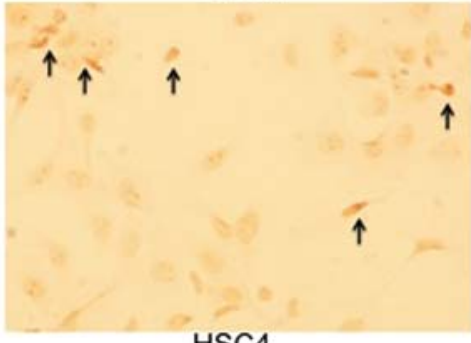

HSC4

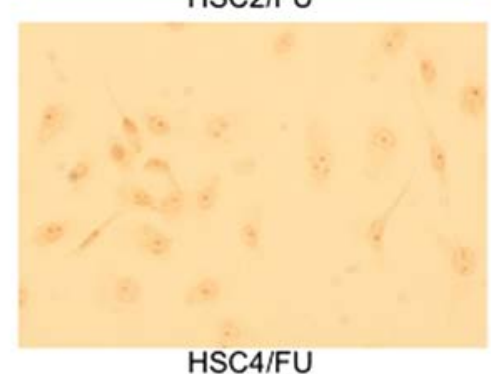

$\mathrm{HSC} 4 / \mathrm{FU}$

5-FU $(4 \mu \mathrm{g} / \mathrm{ml}) 48 \mathrm{~h}$ treatment $\uparrow$ Apoptotic cells

\section{B}

TUNEL positive cell number

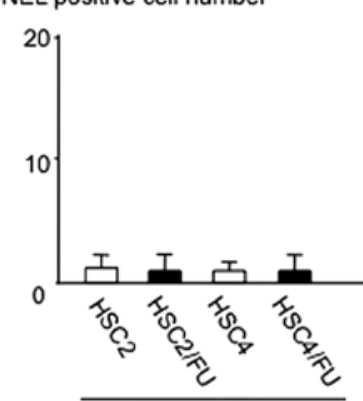

Untreated control

\section{$+$}
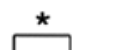


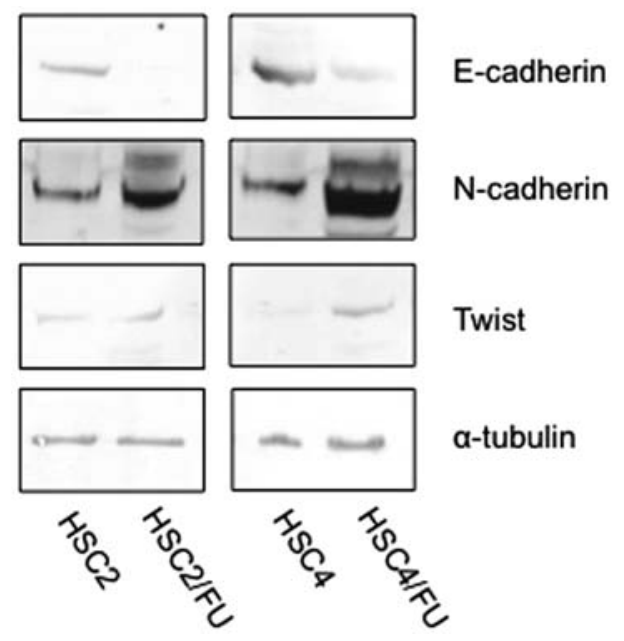

Figure 5. EMT related factors expression assay. Western blot analysis was performed to investigate protein levels of E-cadherin, $\mathrm{N}$-cadherin and Twist. Western blot analysis showed decreased E-cadherin and increased $\mathrm{N}$-cadherin and Twist in the HSC2/FU and HSC4/FU.

detail mechanism of the clinical response to 5-FU chemotherapy is still unclear as cancer cells gain resistance to 5-FU overtime, which is a serious problem for 5-FU based chemotherapy. Although several mechanisms of 5-FU resistance have been investigated (20-22), its definitive mechanism in OSCC is still unclear. In order to understand 5-FU resistance in OSCC, we must establish 5-FU-resistant cancer cell lines and compare them with the parental cancer cells. Several 5-FU-resistant cancer cells have been established (23-26), however, the only OSCC cell line that has been reported to be resistant to 5-FU is SAS (27). In the present report, we describe the establishment of two new 5-FU-resistant OSCC cell lines, HSC2/FU and HSC4/FU that show different EMT characteristics than the parental cell lines.

There was no significant difference in cellular proliferation between $\mathrm{HSC} 2$ and $\mathrm{HSC} 2 / \mathrm{FU}$; however, HSC2/FU tumors grew faster than HSC2 tumors. In the same manner, the cell proliferation speed of $\mathrm{HSC} 4$ was equal to $\mathrm{HSC} 4 / \mathrm{FU}$, though the growth of HSC4/FU tumor was faster than HSC4 tumor (Figs. 1 and 6). Our cell/tumor growth inhibition assay and TUNEL assay results clearly showed the resistant nature of $\mathrm{HSC} 2 / \mathrm{FU}$ and $\mathrm{HSC} 4 / \mathrm{FU}$ cells. This resistance to 5-FU may involve many factors and a number of signaling pathways, but in this study we only emphasize the EMT characteristics of the resistant cell lines.

Loss of E-cadherin is considered to be essential for EMT. There are many transcription factors that can inhibit E-cadherin activity directly (i.e. Twist, Goosecoid, TCF4, SIX1 and FOXC2) or indirectly [i.e. SNAI1/Snail 1, SNAI2/Snail 2, ZEB1, ZEB2, E47 and KLF8 (Kruppellike factor 8)] (28). Our 5-FU-resistant cells (HSC2/FU and $\mathrm{HSC} 4 / \mathrm{FU}$ ) showed decreased E-cadherin expressions and increased $\mathrm{N}$-cadherin and Twist expressions as well as typical morphologic phenotypes of EMT, which may reflect an important process of developing resistance to 5-FU. Though further investigations are needed to clarify the mechanisms of 5-FU resistance, recovery of EMT changes in 5-FU-resistant cells may be a potential therapeutic target
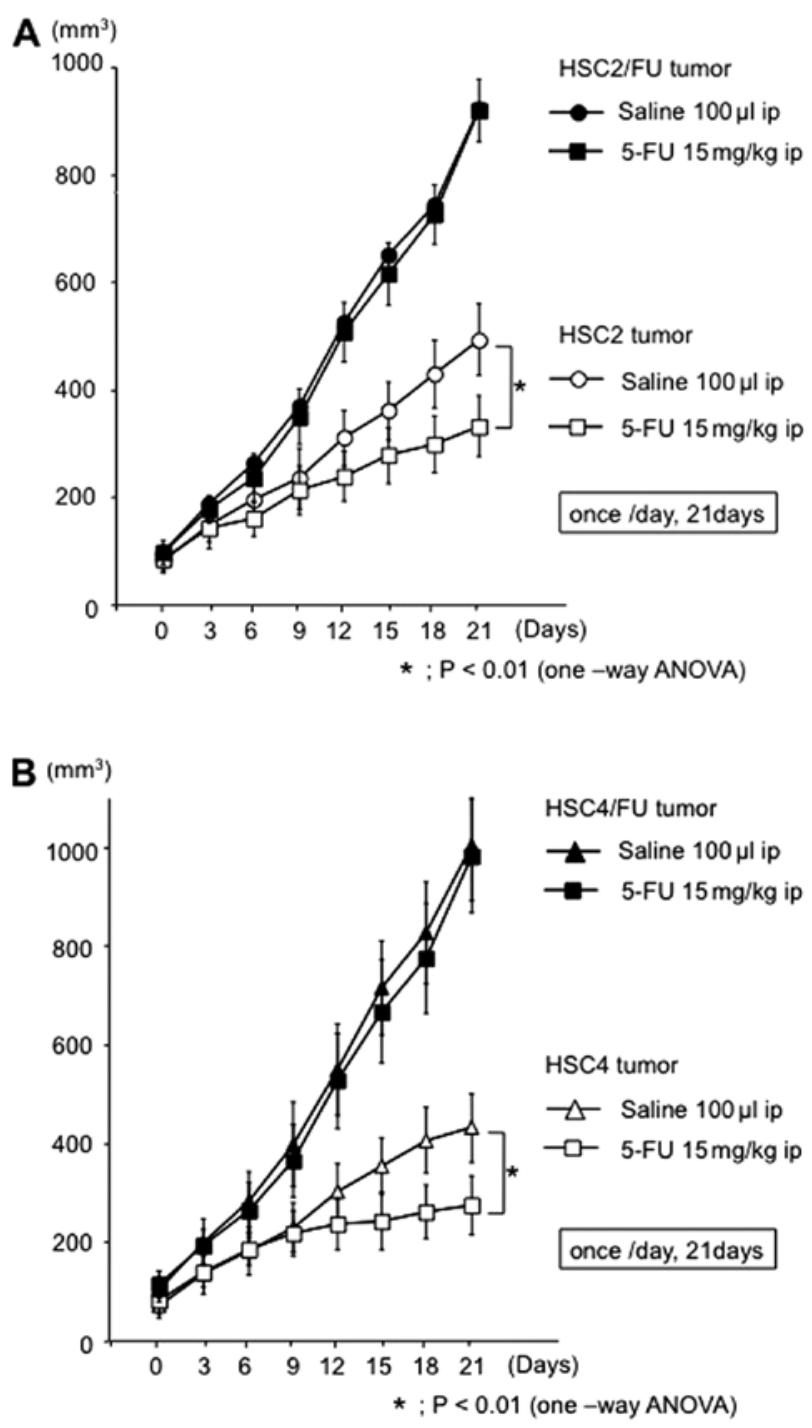

Figure 6. Tumor growth assay. Cells $\left(1 \times 10^{6}\right)$ were inoculated into the backs of nude mice. When the tumors reached $100-150 \mathrm{~mm}^{3}$ in volume, they were treated with $5-\mathrm{FU}(15 \mathrm{mg} / \mathrm{kg} /$ day $)$ for 3 weeks. Tumor volume was measured every two days. (A) HSC2/FU tumors are resistant to 5-FU when compared to HSC2 tumors. (B) HSC4/FU tumors are resistant to 5-FU when compared to HSC4 tumors. Error bars represent the standard error of the mean from five mice results $(n=5)$.

for development of the new strategy for advanced and/or recurrent OSCC treatment.

In conclusion, we found EMT changes in $\mathrm{HSC} 2 / \mathrm{FU}$ and $\mathrm{HSC} 4 / \mathrm{FU}$. However, multiple mechanisms may lead to 5-FU resistance in OSCC. It is reported that, 5-FU metabolism and activity of 5-FU transport are closely linked to 5-FU resistance $(29,30)$. Uchibori et al (26) showed that, downregulated RNRs (a key enzyme in 5-FU metabolism) and upregulated MRP5 (an energy-dependent ATP-binding cassette transporter protein) might confer 5-FU resistance in hepatocellular carcinoma. Nagata et al reported that overexpression of cellular inhibitor of apoptosis proteins 2 (cIAP2) contributes to 5-FU resistance in OSCC (27). In their report, the 5-FU-resistant OSCC cells (SAS/FR2) were not morphologically distinct from the parental cell line (SAS) though SAS/FR2 and SAS had spindle-shaped 

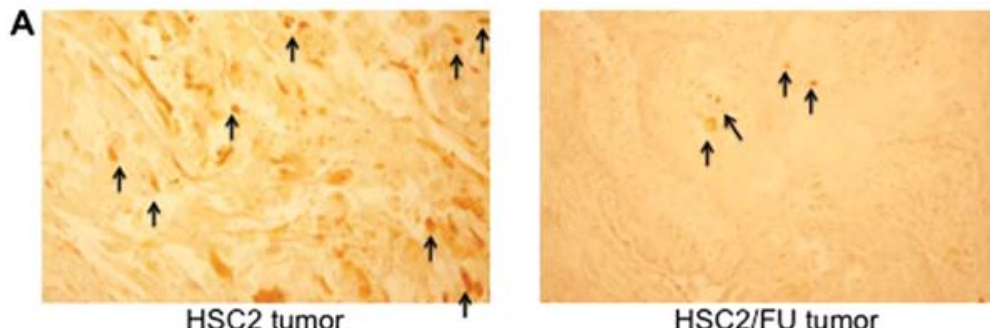

HSC2/FU tumor
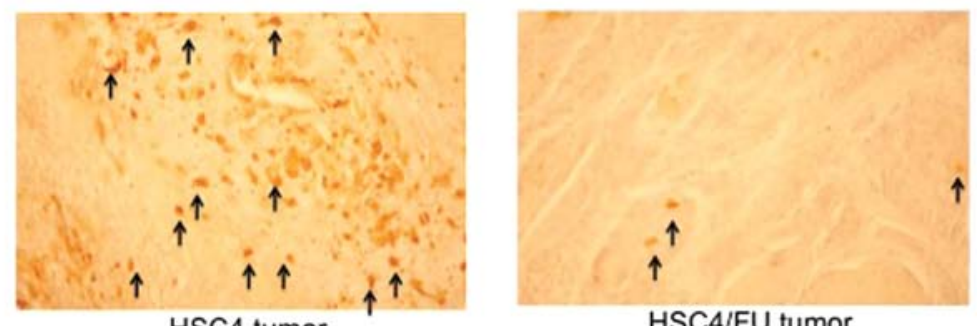

HSC4 tumor

HSC4/FU tumor

$5-\mathrm{FU}(15 \mathrm{mg} / \mathrm{kg}) 3$ weeks administration $\uparrow$ Apoptotic cells

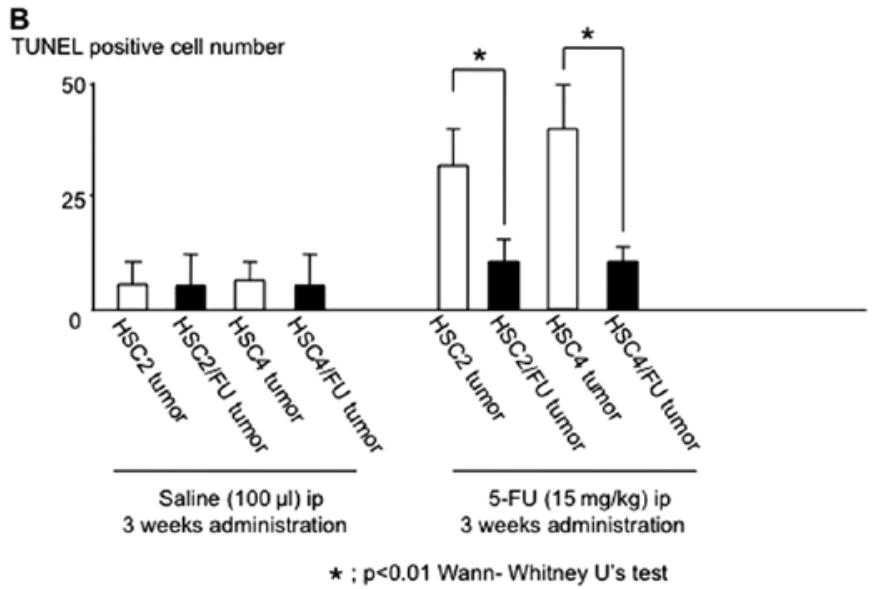

Figure 7. TUNEL assay. (A) To evaluate the effect of 5-FU on the HSC2 tumor, HSC2/FU tumor, HSC4 tumor and HSC4/FU tumor, a TUNEL assay was performed to confirm the apoptotic changes. TUNEL staining shows a dramatic increase in the number of cells that were stained brown, which indicates that apoptosis occurred in HSC2 tumor and HSC4 tumor exposed to 5-FU (15 mg/kg/day) for 3 weeks. 5-FU-induced apoptosis is inhibited in the HSC2/FU tumor and HSC4/FU tumor. (B) The TUNEL assay significantly decreased number of apoptotic cells in the 5-FU-resistant tumors after treatment with 5-FU. Error bars represent the standard error of the mean from five mice results $(n=5)$.

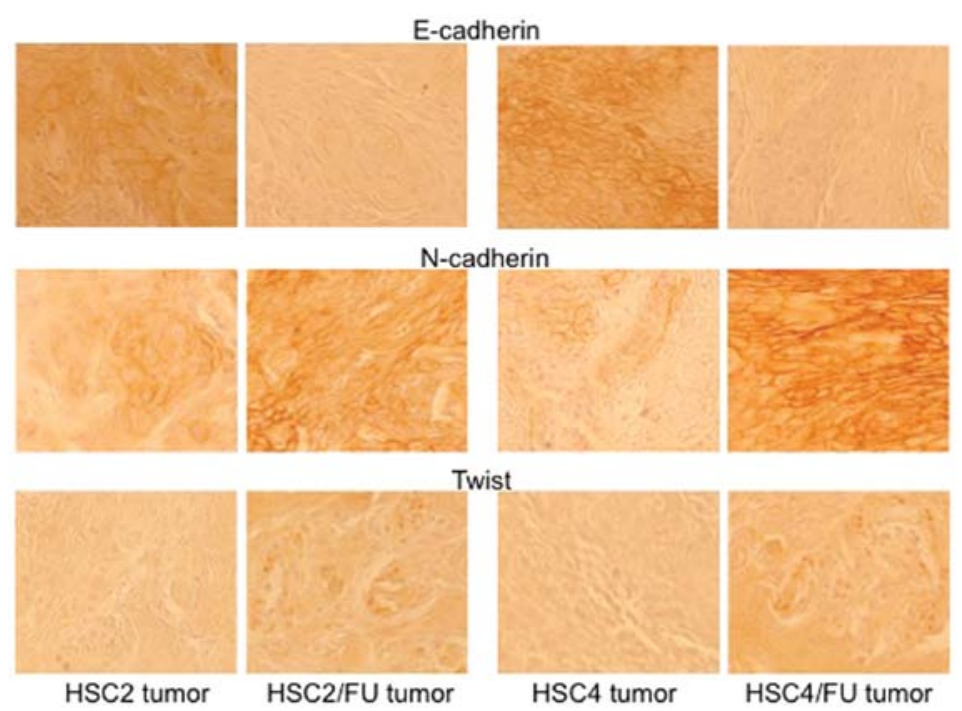

Figure 8. Expression assay of EMT related factors. Immunohistochemical staining was performed to investigate protein levels of E-cadherin, N-cadherin and Twist on nude mouse tumors. Immunohistochemistry showed the expression of E-cadherin was markedly decreased in 5-FU-resistant tumors, and the expressions of $\mathrm{N}$-cadherin and Twist were increased in 5-FU-resistant tumors. 
morphology. (it was unclear whether SAS/FR2 showed EMT changes). Our 5-FU-resistant OSCC cell line associated with EMT may show high degree of resistance to radiation as well as chemotherapy. HSC2/FU demonstrated stronger resistance to radiation as well as cisplatin than HSC2 (data not shown). Further investigations are required; however, the 5-FU-resistant OSCC cells (HSC2/FU and HSC4/FU) might be useful in vitro and in vivo models for understanding the 5-FU-resistant mechanisms in OSCC.

\section{Acknowledgements}

This study was supported in part by a Grant-in-Aid from the Japanese Ministry of Education, Science and Culture.

\section{References}

1. Rautava J, Luukkaa M, Heikinheimo K, Alin J, Grenman R and Happonen RP: Squamous cell carcinomas arising from different types of oral epithelia differ in their tumor and patient characteristics and survival. Oral Oncol 43: 911-919, 2007.

2. Funk GF, Karnell LH, Robinson RA, Zhen WK, Trask DK and Hoffman HT: Presentation, treatment, and outcome of oral cavity cancer: a national cancer data base report. Head Neck 24: 165-180, 2002.

3. Mehrotra R, Singh MK, Pandya S and Singh M: The use of an oral brush biopsy without computer - assisted anaylsis in the oral lesions: a study of 94 patients. Oral Surg Oral Med Oral Pathol Oral Radiol Endod 106: 246-253, 2008.

4. Lawoyin JO, Lawoyin DO and Aderinokun G: Intra-oral squamous cell carcinoma in Ibadan: a review of 90 cases. Afr $\mathbf{J}$ Med Med Sci 26: 187-188, 1997.

5. Chaudhuri NK, Montag BJ and Heidelberger C: Studies on fluorinated pyrimidines. III. The metabolism of 5-fluorouracil2-C14 and 5-fluoroorotic-2-C14 acid in vivo. Cancer Res 18: 318-328, 1958.

6. Greenburg G and Hay ED: Epithelia suspended in collagen gels can lose polarity and express characteristics of migrating mesenchymal cells. J Cell Biol 95: 333-339, 1982.

7. Yang AD, Fan F, Camp ER, van Buren G, Liu W, Somcio R, Gray MJ, Cheng H, Hoff PM and Ellis LM: Chronic oxaliplatin resistance induces epithelial-to-mesenchymal transition in colorectal cancer cell lines. Clin Cancer Res 12: 4147-4153, 2006

8. Thiery JP, Acloque H, Huang RY and Nieto MA: Epithelialmesenchymal transitions in development and disease. Cell 139: 871-890, 2009.

9. Thiery JP: Epithelial-mesenchymal transitions in tumour progression. Nat Rev Cancer 2: 442-454, 2002.

10. Thiery JP and Chopin D: Epithelial cell plasticity in development and tumor progression. Cancer Metastasis Rev 18: 31-42, 1999.

11. Kong B, Michalski CW and Kleeff J: Tumor initiating cells in pancreatic cancer: A critical view. World J Stem Cells 1: 8-10, 2009.

12. Gupta PB, Chaffer CL and Weinberg RA: Cancer stem cells: mirage or reality? Nat Med 15: 1010-1012, 2009.

13. Lee JH, Kim MC, Oh SY, Kwon HC, Kim SH, Kwon KA, Lee S, Jeong JS, Choi SR and Kim HJ: Predictive value of in vitro adenosine triphosphate-based chemotherapy response assay in advanced gastric cancer patients who received oral 5-fluorouracil after curative resection. Cancer Res Treat 43: 117-123, 2011.

14. Gamelin EC, Danquechin-Dorval EM, Dumesnil YF, Maillart PJ, Goudier MJ, Burtin PC, Delva RG, Lortholary AH, Gesta PH and Larra FG: Relationship between 5-fluorouracil (5-FU) dose intensity and therapeutic response in patients with advanced colorectal cancer receiving infusional therapy containing 5-FU. Cancer 77: 441-451, 1996.

15. Murakami Y, Uemura K, Sudo T, Hayashidani Y, Hashimoto Y, Ohge $\mathrm{H}$ and Sueda T: Impact of adjuvant gemcitabine plus S-1 chemotherapy after surgical resection for adenocarcinoma of the body or tail of the pancreas. J Gastrointest Surg 13: 85-92, 2009.
16. Huang CL, Yokomise H, Kobayashi S, Fukushima M, Hitomi S and Wada $\mathrm{H}$ : Intratumoral expression of thymidylate synthase and dihydropyrimidine dehydrogenase in non-small cell lung cancer patients treated with 5-FU-based chemotherapy. Int J Oncol 17: 47-54, 2000

17. Furusaka T, Asakawa T, Tanaka A, Matsuda H and Ikeda M: Efficacy of multidrug superselective intra-arterial chemotherapy (docetaxel, cisplatin, and 5-fluorouracil) using the Seldinger technique for tongue cancer. Acta Otolaryngol 132: 1108-1114, 2012

18. Lorch JH, Goloubeva O, Haddad RI, Cullen K, Sarlis N, Tishler R, Tan M, Fasciano J, Sammartino DE and Posner MR; TAX 324 Study Group: Induction chemotherapy with cisplatin and fluorouracil alone or in combination with docetaxel in locally advanced squamous-cell cancer of the head and neck: long-term results of the TAX 324 randomised phase 3 trial. Lancet Oncol 12: 153-159, 2011.

19. Blanchard P, Bourhis J, Lacas B, Posner MR, Vermorken JB, Hernandez JJ, Bourredjem A, Calais G, Paccagnella A, Hitt R, Pignon JP; Meta-Analysis of Chemotherapy in Head and Neck Cancer, Induction Project, Collaborative Group: Taxane-cisplatin-fluorouracil as induction chemotherapy in locally advanced head and neck cancers: an individual patient data meta-analysis of the meta-analysis of chemotherapy in head and neck cancer group. J Clin Oncol 31: 2854-2860, 2013.

20. Peters GJ, Backus HH, Freemantle S, van Triest B, Codacci-Pisanelli G, van der Wilt CL, Smid K, Lunec J, Calvert AH, Marsh S, McLeod HL, Bloemena E, Meijer S, Jansen G, van Groeningen CJ and Pinedo HM: Induction of thymidylate synthase as a 5-fluorouracil resistance mechanism. Biochim Biophys Acta 1587: 194-205, 2002.

21. Longley DB, Harkin DP and Johnston PG: 5-Fluorouracil: mechanisms of action and clinical strategies. Nat Rev Cancer 3: 330-338, 2003.

22. Harada K, Kawashima Y, Yoshida H and Sato M: Thymidylate synthase expression in oral squamous cell carcinoma predicts response to S-1. Oncol Rep 15: 1417-1423, 2006.

23. Johnston PG, Drake JC, Trepel J and Allegra CJ: Immunological quantitation of thymidylate synthase using the monoclonal antibody TS 106 in 5-fluorouracil-sensitive and -resistant human cancer cell lines. Cancer Res 52: 4306-4312, 1992.

24. Plasencia C, Rooney PH, Taron M, Martinez-Balibrea E, McLeod HL and Abad A: Chromosomal imbalance maps of human 5FU-resistant colorectal cancer cell lines: implications in the analysis of 5FU-acquired resistance mechanisms. Int J Oncol 22: 945-953, 2003.

25. Tanaka T, Bai T and Toujima S: Establishment and characterization of monoclonal 5-fluorouracil-resistant cell lines derived from human endometrial adenocarcinoma. Int J Oncol 37: 731-736, 2010.

26. Uchibori K, Kasamatsu A, Sunaga M, Yokota S, Sakurada T, Kobayashi E, Yoshikawa M, Uzawa K, Ueda S, Tanzawa H and Sato N: Establishment and characterization of two 5-fluorouracil-resistant hepatocellular carcinoma cell lines. Int J Oncol 40: 1005-1010, 2012.

27. Nagata M, Nakayama H, Tanaka T, Yoshida R, Yoshitake Y, Fukuma D, Kawahara K, Nakagawa Y, Ota K, Hiraki A and Shinohara M: Overexpression of cIAP2 contributes to 5-FU resistance and a poor prognosis in oral squamous cell carcinoma. Br J Cancer 105: 1322-1330, 2011.

28. Peinado H, Olmeda D and Cano A: Snail, Zeb and bHLH factors in tumour progression: an alliance against the epithelial phenotype? Nat Rev Cancer 7: 415-428, 2007.

29. Pratt S, Shepard RL, Kandasamy RA, Johnston PA, Perry W III and Dantzig AH: The multidrug resistance protein 5 (ABCC5) confers resistance to 5-fluorouracil and transports its monophosphorylated metabolites. Mol Cancer Ther 4: 855-863, 2005 .

30. Nakano Y, Tanno S, Koizumi K, Nishikawa T, Nakamura K, Minoguchi M, Izawa T, Mizukami Y, Okumura T and Kohgo Y: Gemcitabine chemoresistance and molecular markers associated with gemcitabine transport and metabolism in human pancreatic cancer cells. Br J Cancer 96: 457-463, 2007. 